\title{
UNIDADES GEOMORFOLOGICAS DA BACIA DO RIO NEVERI, VENEZUELA
}

\author{
Maria Jose Entrena Pineda ${ }^{(a)}$, Rhael David Lara Partida ${ }^{(b)}$, Mario Trentin ${ }^{(c)}$, Luís Eduardo de \\ Souza Robaina ${ }^{(d)}$
}

(a) Departamento de Geociências/ Universidade Federal de Santa Maria, mariajoseentrena@ gmail.com

(b) Departamento de Geociências/ Universidade Federal de Santa Maria, rhael.lara5@gmail.com

(c) Departamento de Geociências/ Universidade Federal de Santa Maria romario.trentin@gmail.com

(d) Departamento de Geociências/Universidade Federal de Santa Maria, lesrobaina@yahoo.com.br

\section{EIXO: SISTEMAS GEOMORFOLOGICOS: ESTRUTURA, DINÂMICAS E PROCESSOS}

\section{Resumo}

O avanço das geotecnologias e informática aplicadas no campo da geomorfologia é crescente, o uso de técnicas de inferência espacial para identificação de distintas unidades do relevo, apoia a análise digital do relevo. Nesse sentido, o presente trabalho apresenta o experimento que identificou sete unidades geomorfologicas, apoiando-se em atributos topográficos derivados do MDE da bacia hidrografica do rio Neveri, Venezuela. Os atributos topográficos empregados foram: altitude, declividade. Baseia-se na proposta de mapeamento semi-automatizado, que consiste no cruzamento dos atributos topograficos utilizando com base nos valores da altitude, declividades de $0 \%$ a $15 \%, 15$ $45 \%$ e maior que $45 \%$. A area de estudo é composta de relevos abruptos nas partes altas e médio curso da bacia e planas no curso baixo do rio, apresentando áreas de erosão e sedimentação.

Palavras chave: bacia hidrográfica, geomorfologia, atributos topográficos, unidades geomorfologicas

\section{Introdução}

A Geomorfologia é um dos principais ramos da geografia física, a sua abordagem permite a compreensão do relevo como um elemento dinâmico da superfície da Terra e são incorporados como um espaço onde os processos sociais são materializados. Seu desenvolvimento no espaço temporário permite a compreensão dos processos de dinâmica da superfície.

O Relevo é o resultado da ação de forças opostas, que pode ser sintetizado em atividades tectônicas, os mecanismos estruturais e morfoclimáticos ao longo do tempo geológico, estes podem ocorrer simultaneamente ou sucessivamente (MASCERJAKOV, 1968, 1990 ROSS; GUERRA e GUERRA, 2005).

O processo de identificar formas de relevo é realizado por sua origem, estrutura, natureza das rochas, clima e fatores endógenos e exógenos responsável pela modelagem de certos elementos da superfície da terra, é por esta razão que estudos geomorfológicos contribuiem no planejamento e na conservação dos recursos naturais, estabelecendo esquemas racionais e formas de usar estes, sem abruptamente alterar o equilíbrio. 
Neste sentido ROSS (1990) aborda que as formas que o relevo apresentam a consequência da atuação destas forças, já que mediante as variações topográficas e morfológicas se abre um espaço para a atuação da força de gravidade, a qual é a responsável pelas deslocações de matéria e energia líquida ou sólida desde as partes altas às partes mais baixas durante um processo contínuo de desgaste das partes elevadas e de acumulação dos terrenos mais baixos e desta forma estabelece-se a interface litosfera-atmosfera-hidrosfera-biosfera, a qual desempenha um papel importante nos estudos ambientais.

Neste contexto, Trentin e Robaina (2012) propõem que o estudo da geomorfologia permite a análise do espaço-temporal, dos processos que modelam o relevo terrestre, onde é possível identificar, analisar e, portanto, prever processos de degradação ambiental, os quais se encontram unidos aos elementos físicos em um determinado espaço geográfico. Desta forma a análise geomorfológica perfila-se como um importante instrumento de análise e determinação de ações que permitam mitigar para evitar impactos no ambiente.

A caracterização geomorfológica representa o produto integral das formas e dos processos naturais e antrópicos, tanto no passado como no presente dos componentes do meio físico. Neste sentido, Penteado (1985), destaca que a classificação geomorfológica engloba as características morfométricas e morfológicas e os processos morfodinámicos e morfogenéticos do relevo.

A análise geomorfológica apresenta as premissas para compreender as diferentes dinâmicas das paisagens presentes na superfície terrestre, onde se amplia o entendimento dos processos superficiais que originam as formas de relevo, partindo-se dos principais atributos do meio físico. Esses processos geradores de formas de relevo não são homogêneos na superfície terrestre, portanto, se encontram estreitamente relacionados com fatores temporários e espaciais nas evidências do relevo, assim como manifestam a necessidade de estabelecer uma sistematização dos dados para uma representação integrada (PAULA, 2006).

A classificação de tais evidências fazem parte do conjunto de dados sobre os quais se baseiam as descrições dos elementos do relevo. As formas de relevo apresentam uma distinção na morfologia e a sua vez em função de fatores como o substrato rochoso, estrutura geológica, solo, clima, condicionam sua evolução, tendo como resultado diferentes combinações de características. 


\section{OS DESAFIOS DA GEOGRAFIA FÍSICA NA FRONTEIRA DO CONHECIMENTO \\ Instituto de Geociências - Unicamp \\ Campinas - SP \\ 28 de Junho à 02 de Julho de 2017}

As formas de relevo e as litologias constituem o substrato onde se desenvolvem atividades humanas, é por esta razão que zoneamento que determinem unidades homogêneas são fundamentais para compreender os processos geomorfológicos e a interferência das ações humanas no médio físico.

Os sistemas de cartografia geomorfológica nem sempre incluem todos os aspectos do relevo com a mesma ênfase sistemático. Na maioria dos casos incluem-se informações geológicas, particularmente de litologias e de materiais não consolidados ou de formações superficiais (FLORENZANO, 2008).

A modelagem geomorfológica assistida pela disponibilidade de Modelos Digitais de Terreno e a capacidade otimizada de processamento em ambientes de Sistemas de Informação Geográfica (SIG), apresentam condições favoráveis para diversos aplicativos no que se refere a análise digital de relevo, dando suporte na construção de diversas cartografia temática como mapas geomorfológicos, hidrológicos, geotécnicos, mapas de susceptibilidade a processos geoambientais, compartimentação e evolução da paisagem entre outras aplicações (SILVEIRA, 2016).

A bacia hidrográfica pode ser considerada como exemplo de sistema geomorfológico complexo, já que apresenta todas as características inerentes a esse tipo de sistema. Nesse sentido a bacia é um sistema aberto aos fluxos de energia e matéria, onde as entradas do sistema são representadas pela precipitação e as forças tectónicas subjacentes e as saídas pela perda de água e sedimentos. Sua configuração hierarquizada resulta outra característica básica de sistemas geomorfológicos complexos (MATTOS; FILHO, 2004).

Para o caso das bacias hidrográficas, as condições climáticas, geológicas e biogeográficas constituem seu meio. Portanto, condicionam a estrutura da rede de drenagem, e das formas de relevo.

A sensibilidade da paisagem encontra-se definida como a relação presente entre a magnitude de uma mudança e a magnitude de resposta do sistema com respeito a essa mudança, o qual se encontra diretamente relacionado à existência de limites, quanto menos seja a existência de limites de um sistema, maior é a sensibilidade às perturbações e por consequência maior probabilidade de sair de seu estado de estabilidade (THOMAS, 2001). 
Dessa forma, a bacia hidrográfica representa uma unidade de análise para diagnosticar diversas situações dos sistemas ambientais presentes na mesma, bem como gerar insumos que permitam o desenvolvimento dessa área.

De acordo com Botelho, (1999 apud SILVA, 2009), as bacias hidrográficas, como unidade natural de estudo e análise da superfície terrestre, resultam unidades ideais para o planejamento do uso da terra onde é possível reconhecer e estudar as inter-relações existentes entre os diversos elementos da paisagem e os processos que atuam no modelado da superfície terrestre.

Com base nesta discussão o trabalho utiliza como limite de estudo a bacia hidrográfica por apresentar delimitação baseada em características naturais e possibilitar a discussão integrando os elementos que condicionam os processos naturais.

De acordo com Wood (1996) a parametrização do relevo refere-se à representação quantitativa das características morfológicas da paisagem, que são continuamente descritas pelas equações aplicadas, a representação numérica e modelos de altimetria onde os atributos geomorfométricos são derivados. Esses atributos representam mensurações quantitativas das formas do relevo por meio de técnicas empregadas nos Sistemas de Informações Geográficas (SIG) (HENGL, 2003; WOOD, 1996).

A importância da compartimentação do relevo reside na utilização de diferentes aplicações no domínio do planeamento e ordenamento do território, zoneamento ambiental, mapeamento geomorfológicos, pedológicos, de susceptibilidade geoambiental, entre outros (TRENTIN; ROBAINA; SILVEIRA, 2015). A compartimentação geomorfologica é suportada por atributos quantitativos (variáveis) morfométricas do componente topográfico, que representam elementos quantificáveis na superfície da terra. Estes atributos topográficos podem ser parametrizados utilizando variáveis como a altitude, declividade, entre outros (GUADAGNIN; TRENTIN, 2014).

Os elementos acima mencionados de forma simplificada têm a capacidade de descrever a dinâmica da superfície da Terra, apresentando vestígios do seu passado, do seu presente e como o seu futuro (com base nas condições atuais); e, assim, gerar estudos em vários níveis de detalhe, podendo vir a ser fontes de zoneamentos de diagnóstico e ambientais.

A bacia pode ser considerada como um exemplo de sistema complexo geomorfológico porque tem todas as características inerentes a um tal sistema. Nesse sentido, a bacia é aberta para os fluxos de energia e um sistema, em que as entradas são representadas pela precipitação e a forças e saídas tectônicas subjacente para a perda de água e sedimentos. Sua configuração hierárquica é outra característica básica dos sistemas geomorfológicos complexos (MATTOS; FILHO, 2004). 
Independentemente da perspectiva escolhida para o sistema de análise geomorfológico (bacia hidrográfica), a identificação dos subsistemas não pode ser executada individualmente com cada um dos seus componentes: estrutura, função e organização, que são o resultado das inter-relações entre eles (MATTOS; FILHO, 2004).

Assim, a bacia representa uma unidade de análise para o diagnóstico de várias situações de sistemas ambientais presentes nele, e geram entradas para o desenvolvimento desta.

Com base nessa discussão o trabalho utiliza uma área de estudo de bacia hidrográfica para fazer uma delimitação com base em recursos naturais e permitir a discussão integral dos elementos que determinam os processos naturais.

No cenário venezuelano existe grande demanda e carência por mapas geomorfológicos. Isso se deve às diversas variáveis envolvidas no seu processo de elaboração: falta de cartas topográficas em escala compatível e com ampla abrangência de todo território nacional, a grande extensão de áreas a serem mapeadas, a dificuldade de acesso em muitas regiões, o elevado custo dos levantamentos, entre diversos outros fatores.

Porém, os atuais avanços e desenvolvimento no campo da informática, associada ao avanço das geotecnologias, potencializam o emprego de técnicas digitais na análise do relevo, apoiadas na representação da superfície terrestre na forma de Modelos Digitais Numéricos (MDN), Modelos Digitais do Terreno (MDT) ou Modelos Digitais de Elevação (MDE), que permitem extrair variáveis que representam a morfologia do relevo e podem contribuir com o avanço da cartografia geomorfológica. Desta forma, o presente estudo foi realizado na bacia hidrográfica do rio Neverí, localizada na região nordeste da Venezuela nos estados Anzoátegui e Sucre, cuja área é de 137.671,09 ha (Figura 1), por meio de técnicas de geoprocessamento associadas à análise digital do relevo onde determinou-se a representação das formas do relevo, com emprego de atributos topográficos obtidos de um Modelo Digital do Elevação, elaborando-se a delimitação de unidades geomorfológicas.

A inferência de unidades apoiada no mapeamento semi-automatizado do relevo segue a proposta de Iwahashi e Pike (2007), que emprega técnica de classificação não-supervisionada de formas do terreno por meio de árvore de decisões com base nos valores médios de duas variáveis geomorfométricas (hipsometria, declividade) derivadas de um MDE. 



Figura 1. Localização da Bacia Hidrográfica do rio Neverí, Venezuela

\section{Materiais e Metodos}

As etapas operacionais feitas com auxílio de ferramentas de geoprocessamento em ambiente SIG foram: a) obtenção do MDE pelas curvas geradas no projeto PITSA (1998); b) geração dos atributos topográficos do relevo (hipsometria e declividade; c) cálculo dos valores médios para discretização das variáveis e operações de álgebra de mapas para as combinações; d) organização e quantificação dos resultados obtidos pela matriz.

Na primeira etapa os dados de elevação foram obtidos do MDE a resolução espacial de 10 metros, seguidamente, desse MDE foram gerados os atributos topográficos do relevo no software ArcGIS 10.1(ESRI, 2013). Para a obtenção da declividade utilizou-se das derivadas direcionais e do modelo proposto por Horn (1981), A declividade corresponde a um dos mais importantes parâmetros na análise das vertentes, pois representa sua inclinação. Estas informações foram discretizadas em três classes cujo limites são $0-15 \% ; 15-45 \% ;>45 \%$. As vertentes com altas declividades estão mais sujeitas a processos denudacionais, enquanto as de baixa são propícias aos processos agradacionais. 


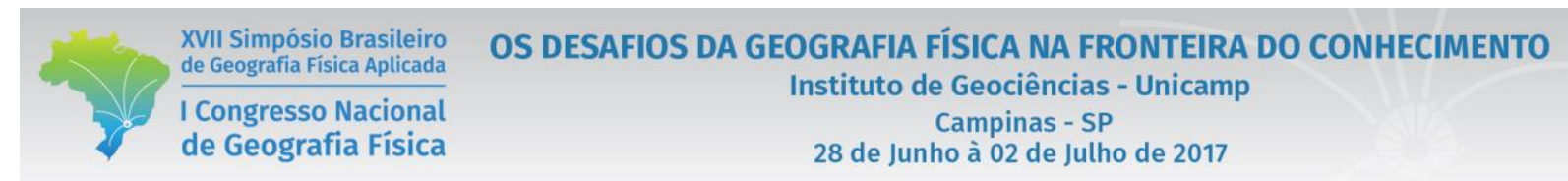

A etapa seguinte consistiu em calcular os respectivos valores dos dois atributos topográficos: hipsômetria (amplitude), declividade (porcentagem) logo foi realizado o cruzamento dessas informações para obter uma matriz com as informações e delimitar as unidades geomorfologicas. (Figura 3).

Esse processo foi realizado com as combinações dos atributos topograficos, onde cada uma das variáveis determina as possibilidades do agrupamento das unidades geomorfológicas em sete (7) unidades geomorfologicas (Figura 2).



Figura 2 - Fluxograma apresentando a árvore de decisão utilizada para a definição das unidades geomorfométricas.

\section{Resultados}

Foram obtidos os atributos altitude, declividade, relevo sombreado para definir as sete unidades geomorfológicas. A área de estudo apresenta como menor cota altimétrica 0 (zero) metros, junto ao delta do rio Neverí onde o rio deságua no Mar Caribe, a maior cota é de 2.446 metros, resultando em uma amplitude altimétrica de $2.446 \mathrm{~m}$. A tabela I apresenta as áreas e porcentagem da área na bacia hidrografica do río Neverí e a figura 3 apresenta as unidades geomorfológicas na bacia hidrográfica. 

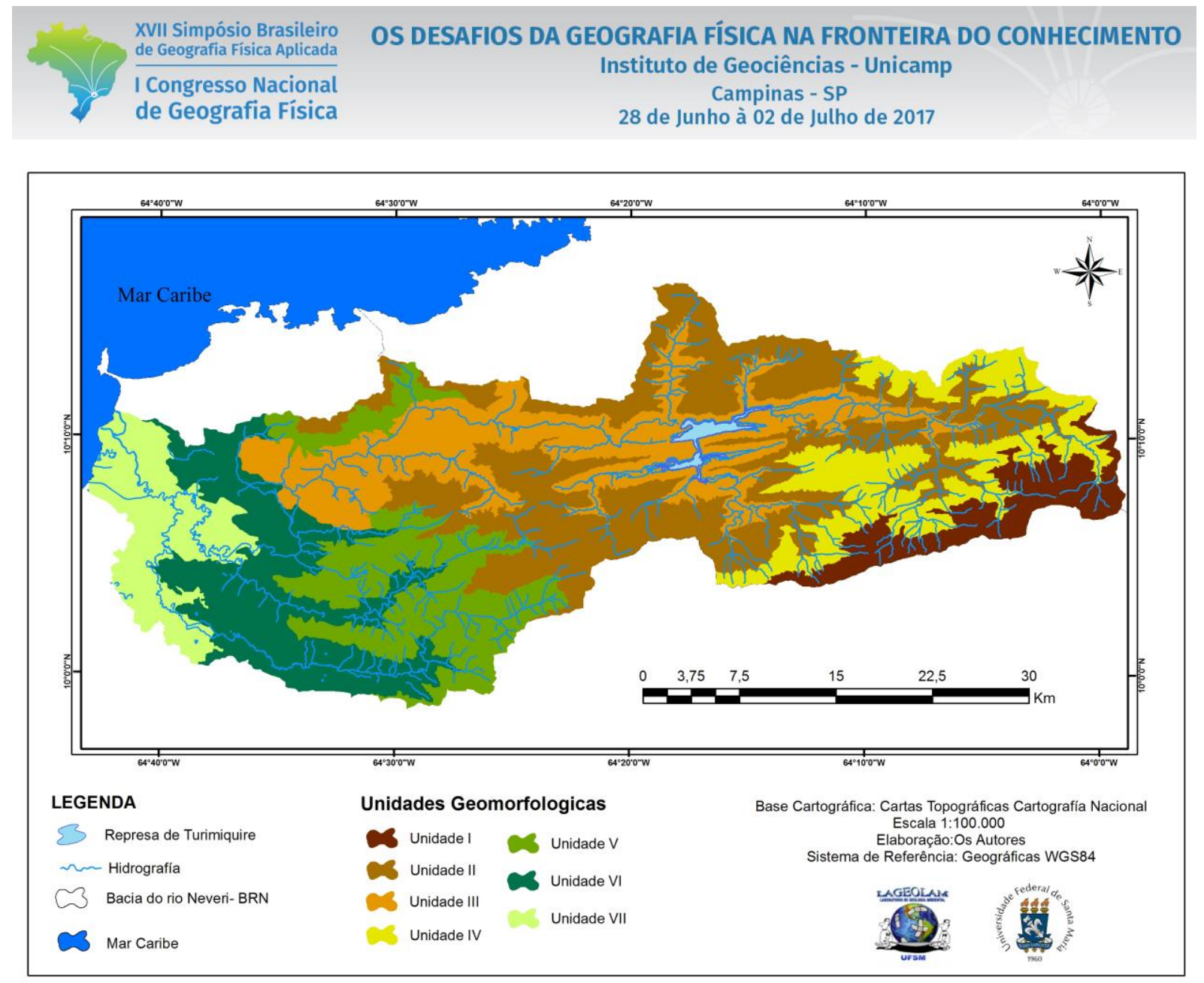

Figura 3- Mapa das unidades geomorfológicas da bacia hidrográfica do rio Neverí

Tabela I - Áreas e respectivas porcentagens das unidades geomorfológicas da bacia hidrográfica do rio Neverí

\begin{tabular}{l|l|l}
\hline \multicolumn{1}{c|}{ Unidade } & \multicolumn{1}{c}{ Área (Ha) } & \multicolumn{1}{c}{ Porcentagem (\%) } \\
\hline Unidade I & $8.366,56$ & 6,08 \\
\hline Unidade II & $35.251,12$ & 25,95 \\
\hline Unidade III & $28.702,03$ & 20,85 \\
\hline Unidade IV & $14.838,14$ & 10,78 \\
\hline Unidade V & $18.304,26$ & 13,30 \\
\hline Unidade VI & $19.299,45$ & 11,29 \\
\hline Unidade VII & $11.244,22$ & 8,17 \\
\hline
\end{tabular}

Fonte: Os autores 


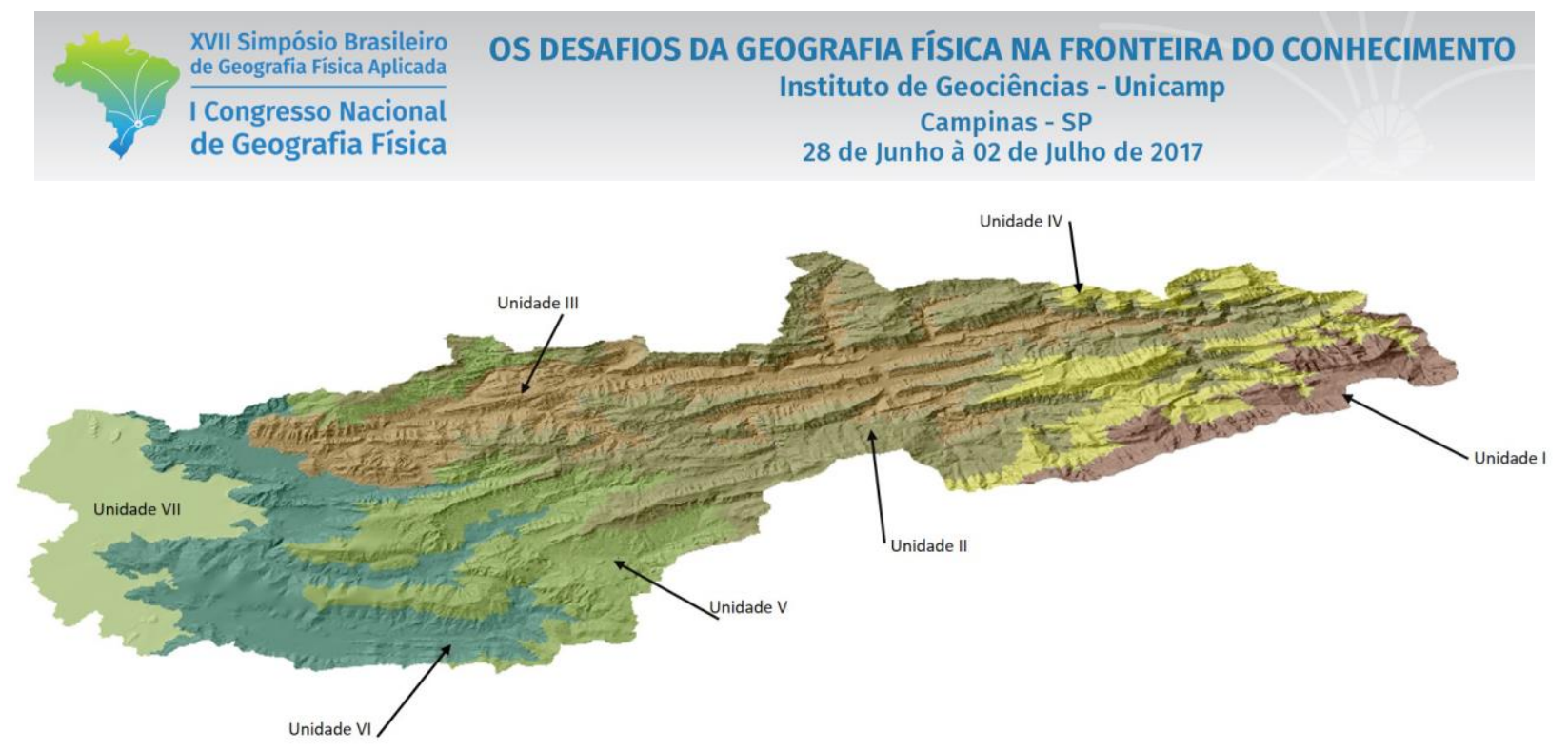

Figura 4- Sínteses das unidades geomorfológicas da bacia hidrográfica do rio Neverí

Unidade I

A unidade I apresenta uma área de 8.366,56 ha, representando o 6,08\% da superficie da bacia, compreende as áreas mais altas da bacia, localizada na parte sudeste. As formas do relevo são representadas por montanhas fortemente escarpadas com declividades maiores de $45 \%$.

\section{Unidade II}

A unidade II contem uma área de 35.251,12 ha, representando o 25,95\% da superfície total, a característica principal das formas do relevo nessa unidade é a presença dum conjunto de montanhas altas, com alinhamentos tectônicos, fortemente escarpadas e declividades superior a 45\%. A localização da unidade é na parte central da bacia.

\section{Unidade III}

Unidade III conta com uma área de 28,702,03 ha, representando o 20,85\% da área total da bacia. Representa formas de relevo controladas pela tectônica com colinas escarpadas e vales encaixados como consequência da resposta da hipsometria com valores de altitude que oscilam entre os 1,000 e 1,300 metros de altitude com declividades de $45 \%$ na parte central e média da bacia.

\section{Unidade IV}

Encontra-se no sul e norte da região oriental da bacia, corresponde a uma área 14,838,14 ha com o 10,78\% da área total da bacia. As altitudes na unidade oscilam entre os 1,400 e 1,700 metros de altitude com declividades maiores de $45 \%$. As formas de relevo são representadas por colinas fortemente escarpadas. 
Unidade $\mathrm{V}$

A unidade V apresenta uma área de 18,304,26 ha, com o 13,30\% da superfície total da bacia. As formas de relevo encontram-se representadas por colinas onduladas na parte oeste da bacia declividades que oscilam entre o $15 \%$ e $45 \%$.

\section{Unidade VI}

Na unidade VI tem predomínio de colinas onduladas com altitudes que oscilam entre 200 e 600 metros e declividades de $15 \%$. A localização da unidade na bacia é na parte oeste. Conta com uma superfície de 19.299,45 ha com o $11,29 \%$ da superfície total. A unidade apresenta áreas de deposição dos sedimentos que provierem das partes altas da bacia.

\section{Unidade VII}

Finalmente a unidade VII é representada pelas áreas planas, com altitudes que oscilam desde o zero (0) metros e 100 metros de altitude, com declividades menores que 15\%. As formas de relevo representativas são a planície aluvial.

\section{Considerações finais}

A utilização dos atributos topograficos na delimitação de unidades geomorfologicas parte da classificação digital das unidades com base nas caracteristicas físicas do meio relacionando diretamente a altitude, declividade com diversas técnicas de geoprocessamento.

Dessa forma permite a divisão da bacia hidrografica em áreas geomorfologicas homogeneas quanto os processos da dinâmica e modelagem da superficie (processos erosivos na parte alta e media e de sedimentação nas partes baixas da bacia). Neste sentido, permitiu o agrupamento da bacia hidrografica do rio Neverí em sete (7) unidades geomorfológicas definidas.

Foi constatado o potencial de aplicação do interpolador topo to raster, disponível como ferramenta no aplicativo ArcMap versão 10.1 (ESRI, 2013) obtendo um modelo digital de elevação hidrologicamente consistente, além dos seus subprodutos.

A compartimentação geomorfométrica se mostrou eficaz com grande aplicabilidade, além de ser uma alternativa viável e oferecer subsídios aos trabalhos de mapeamento preliminares. 


\section{Bibliografia}

CHRISTOFOLETTI, A. Geomorfologia. 2. ed. São Paulo: Edgard Blucher, 1980.188p

ESRI. ArcGis, Spatial Analyst, 3D Analyst. versão 10.1 Environmental Systems Research Institute, 2013

MATTOS, S. H. V. L. DE; FILHO, A. P. Complexidade e estabilidade em sistemas geomorfológicos: uma introdução ao tema. Revista Brasileira de Geomorfologia, p. 11-18, 2004.

GUADAGNIN,P.M; TRENTIN,R.. Compartimentação geomorfométrica da bacia hidrográfica do arroio Caverá - RS Geomorphometric compartmentation of hydrographic basin of the arroio cavera - RS / BRASIL. p. 183-199, 2014.

FLORENZANO, Tereza Gallotti (org.) Geomorfologia: conceitos e tecnologias atuais. São Paulo: Oficina de Textos, 2008.

GUERRA, A. T.; GUERRA, A. J. T. Novo Dicionário Geológico-Geomorfológico. 4 eds. Rio de Janeiro: Bertrand Brasil, 2005. $652 \mathrm{p}$.

HENGL, T. Pedometric mapping: bridging the gaps between conventional and pedometric approaches. Wageningen University, Enschede, 2003. 233p. PhD thesis - Wageningen University.Disponível em:

http://spatial-analyst.net/wiki/index.php?title=Pedometric_mapping:_PhD_thesis Acceso em: 20 jan. 2017.

HORN, B. K. P. Hill shading and the reflectance map. Proceedings of the IEEE, n. 69, v. 01, p. 14-47, 1981

IWAHASHI, J.; PIKE, R. J. Automated classifications of topography from DEMs by an unsupervised nested-means algorithm and a three-part geometric signature.Geomorphology 86(3-4): 409-440, 2007.

MESCERJAKOV, J. P. Les concepts de morphostructure et de morphosculture: un nouvel instrument de l'analyse geomorphologique. Seção de Geomorfologia do Instituto de Geografia da Academia de Ciências das URSS. Moscou, 1968

PENTEADO, M. M. Fundamentos de Geomorfologia. 3 ed. Rio de Janeiro: Fundação IBGE, 1985. 186p

ROSS, J. L. S. O registro cartográfico dos fato geomórficos e a questão da taxonomia do relevo. Revista do Departamento de Geografia, São Paulo, v. 6, p. 17-29, 1992. Disponible em: <http://www.revistas.usp.br/rdg/article/view/47108/50829>. Acceso en: 12 sept. 2016.

TRENTIN, R.; ROBAINA, L. E. S. As Unidades de Relevo como Base para a Compartimentação Geomorfológica da Bacia Hidrográfica do Rio Itu - Oeste do Rio Grande do Sul. In: $9^{\circ}$ SIMPÓSIO NACIONAL DE GEOMORFOLOGIA, 2012, Rio de Janeiro/RJ. Anais... Rio de Janeiro/RJ: Universidade Federal do Rio de Janeiro, 2012.

TRENTIN, R.; ROBAINA, L. E. DE S.; SILVEIRA, C. T. DA. Compartimentação geomorfométrica da bacia hidrográfica do rio itú/rs geomorphometric compartmentation of river basin Itu/RS Revista Brasileira de Geomorfologia. v. 16, n. 2, p. 219-237,2015.

WOOD, J. The geomorphological characterisation of digital elevation models. Leicester, UK, 1996. 185p. PhD Thesis - University of Leicester.Disponível em: http://www.soi.city.ac.uk/ jwo/phd.

ZEVENBERGEN, L.W.; THORNE, C.R. Quantitative Analysis of Land Surface Topography.Earth Surface Processes and Landforms, v.12, p.47-56, 1987 